\title{
A Study of the Kinetics of Hyphal Extension and Branch Initiation of Fungal Mycelia
}

\author{
By A. P. J. T RINCI \\ Microbiology Department, Queen Elizabeth College, \\ Campden Hill, London, $W 87 A H$
}

(Received 28 August 1973; revised I I October 1973)

\begin{abstract}
SUMMARY
Growth of Mucor hiemalis, Geotrichum candidum, Aspergillus nidulans, Neurospora crassa and Penicillium chrysogenum was studied by time lapse photography. The total hyphal length of the mycelium of each species increased at an exponential rate; in $M$. hiemalis exponential growth continued until the mycelium had a total hyphal length in excess of $10 \mathrm{~mm}$. After spore germination there was an initial phase of discontinuous tip production followed by a phase of 'continuous' tip production. The hyphal length and number of tips possessed by a mycelium increased exponentially at approximately the same specific growth rate. The amplitude of the oscillations in the length of the hyphal growth unit of a mycelium decreased progressively during mycelial growth and eventually the growth unit attained a more or less constant value. The results support the hypothesis that mycelial growth involves the duplication of a 'growth unit' which consists of a tip and a certain mean length of hypha.
\end{abstract}

\section{INTRODUCTION}

Plomley (1959) was the first to suggest that filamentous fungi have a 'growth unit' which is duplicated at a constant rate during mycelial growth. This conclusion follows inevitably from the observations that an individual hypha extends at a constant rate (linear growth) whilst the whole mycelium grows exponentially (Zalokar, 1959; Trinci, 1969). Exponential growth is defined by the equation,

$$
\ln M_{1}=\ln M_{0}+\alpha\left(t_{1}-t_{0}\right) \text {, }
$$

where $\ln =$ natural logarithm, $M_{0}=$ mould dry weight at time $t_{0}, M_{1}=$ mould dry weight at time $t_{1}$ and $\alpha$ is a constant known as the specific growth rate. An individual hypha only grows linearly after a period of acceleration (Trinci \& Banbury, 1967; Trinci, I970). If mycelial growth does involve the duplication of a 'growth unit' it follows that the total hyphal length and the number of tips of a mycelium increase exponentially at approximately the same specific growth rate. The ratio total hyphal length:number of tips would thus only be expected to vary between fixed limits during mycelial growth; this ratio has been called the hyphal growth unit (Caldwell \& Trinci, 1973; Trinci, 1973a). The length of the hyphal growth unit of mycelia of Neurospora crassa grown on solid medium was found to be a constant for a given set of environmental conditions (Trinci, 1973a).

In the present investigation the kinetics of hyphal growth and branch initiation were studied by time lapse photography. In particular it was hoped that this study would reveal how the length of the hyphal growth unit varied during the growth of a mycelium. 


\section{METHODS}

Organisms and media. The strains used in the present study were Neurospora crassa, spreading colonial mutant I (kindly supplied by the Fungal Genetics Stock Centre, Humboldt State College Foundation, Arcata, California, U.S.A.), Aspergillus nidulans BwB224 vey, Geotrichum candidum (Queen Elizabeth College (Q.E.C.), strain FI), Mucor hiemalis (Q.E.C. strain ZI3) and Penicillium chrysogenum (Q.E.C. strain PI6). N. crassa was grown on Vogel's medium (Vogel, I956) with I $\%(\mathrm{w} / \mathrm{v})$ sucrose as the carbon source; $A$. nidulans, $G$. candidum and $P$. chrysogenum were grown on DM medium (Trinci, I97I $a$ ); $M$. hiemalis was grown on Difco malt extract agar.

Inoculation, cultivation and photography. Dilute spore suspensions were prepared in $0 \cdot 1 \%$ (v/v) Tween 80 . Petri dishes containing about $\mathrm{Io} \mathrm{ml}$ of media were overlaid with sterile cellophane (P.T. 300, British Cellophane Ltd) and spores were dispersed over the surface with a sterile glass spreader; there were about 20 to 40 spores per plate. The cellophane prevented growth into the medium (Trinci, 1969) and thus ensured that the mycelia grew in a single plane. The Petri dishes were inverted, placed on the stage of a microscope, and spore germination and mycelial growth were recorded with a $35 \mathrm{~mm}$ Shakman Mark I time lapse camera (Shackman \& Sons, Chesham, Buckinghamshire); photographs were usually taken every $15 \mathrm{~min}$. The whole apparatus was housed in a constant temperature room. Measurements of hyphal length and tip number were made on enlarged prints of the photographs at final magnifications of about $\times 70$ for Mucor hiemalis and about $\times 200$ for the other fungi.

Hyphal growth unit. The growth unit (HGU) of a hypha or mycelium is defined by the equation,

$$
\mathrm{HGU}=\frac{\text { Total length of a hypha or mycelium }(\mu \mathrm{m})}{\text { Number of tips }} .
$$

Colony radial growth rate. The radial growth rate of mature colonies on media overlaid with cellophane was determined as described previously (Trinci, 1969; 1973b).

Calculation of the mean rate of tip extension. The mean rate of tip extension $(E$, in $\mu \mathrm{m} / \mathrm{tip} / \mathrm{h}$ ) of a mycelium was calculated from the following equation:

$$
E=\frac{2\left(H_{t}-H_{0}\right)}{B_{0}+B_{t}}
$$

where $H_{0}=$ total hyphal length of the mycelium in $\mu \mathrm{m}$ at zero time, $H_{t}=$ total hyphal length I h later, $B_{0}=$ no. of tips at zero time, and $B_{t}=$ no. of tips I h later. Observations were usually made on mycelia which had a total length of between $\mathrm{I} \cdot 5$ and $3.5 \mathrm{~mm} \mathrm{(200} \mathrm{to}$ $400 \mu \mathrm{m}$ for Penicillium chrysogenum) and possessed to to 20 tips.

\section{RESULTS}

Fig. I to 4 show the increase in hyphal length and number of tips of mycelia of Geotrichum candidum, Aspergillus nidulans, Neurospora crassa and Mucor hiemalis; the final appearance of these mycelia is shown in Fig. 5. The kinetics of the increases in hyphal length and tip number were very reproducible for each species. The total hyphal length of the mycelium of each species increased exponentially; in $M$. hiemalis this exponential growth was continued until the mycelium had a total length of at least $15 \mathrm{~mm}$ (Fig. 4). After spore germination there was an initial period of discontinuous tip production followed by a period of 'continuous' tip production (Figs. I and 4); these two phases merged into one another 


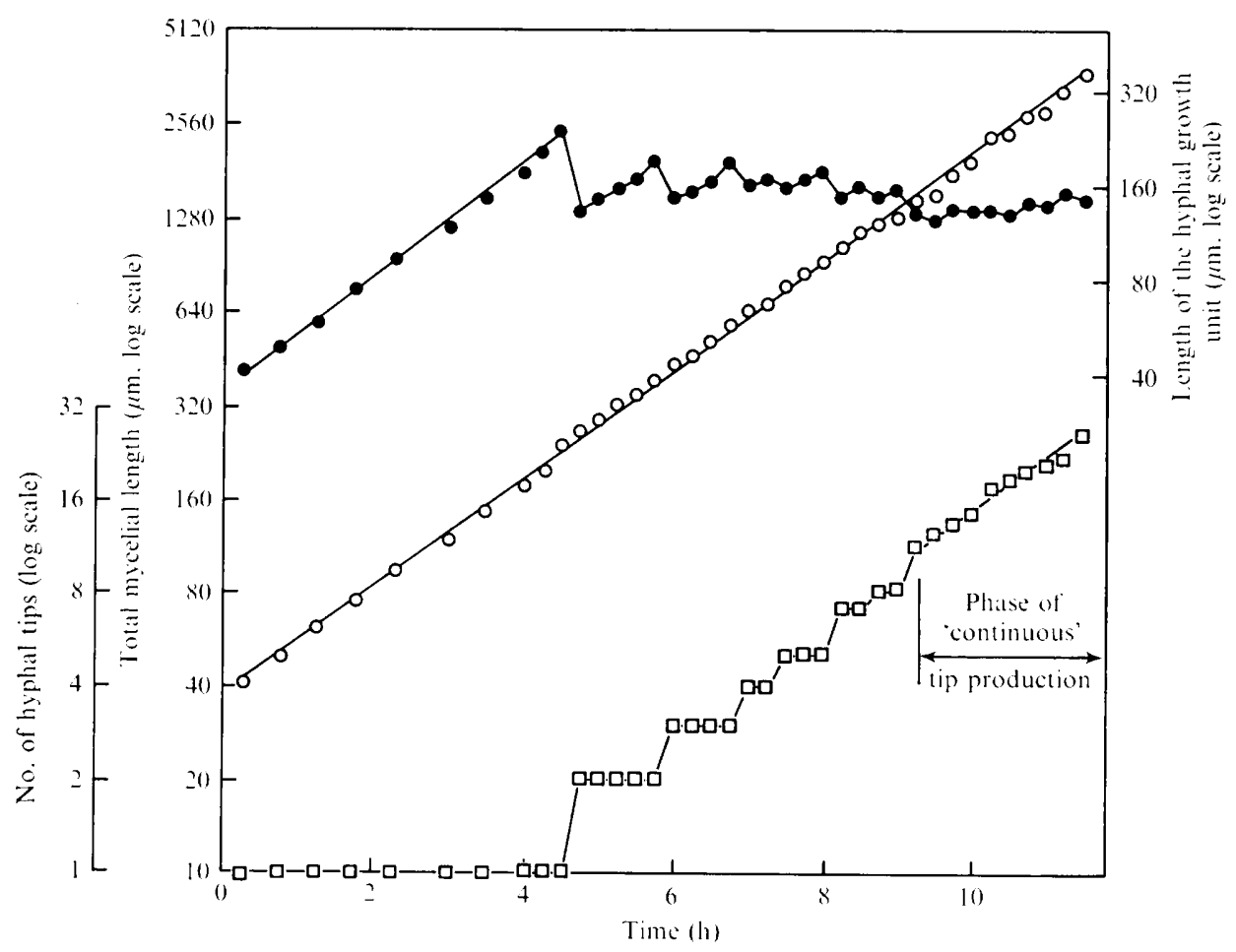

Fig. I. Growth of a mycelium of Geotrichum candidum on solid DM medium at $25{ }^{\circ} \mathrm{C}$. $\square$, No. of tips; $\bigcirc$. total hyphal length;, , hyphal growth unit.

(Fig. 3). The hyphal length and the number of tips possessed by a mycelium increased exponentially at approximately the same specific growth rate (Table I); the tip specific growth rates $\left(\alpha_{t}\right)$ were calculated during the phase of 'continuous' tip production.

The length of the hyphal growth unit oscillated during the growth of a mycelium (Fig. I to 4). The hyphal growth unit increased in length after spore germination until it eventually attained a maximum value; the length of the hyphal growth unit was subsequently halved when the germ-tube produced its first branch. The amplitude of the oscillations in the length of the hyphal growth unit decreased progressively as the mycelium increased in size (Fig. I, 2) until eventually the growth unit attained a more or less constant length (Fig. I, 3 and 4 ).

Mean hyphal extension rate of mycelia. Fig. 6 shows the variation in the mean hyphal extension rate of a mycelium of Geotrichum candidum. The mean hyphal extension rate increased after spore germination until the mycelium possessed about three tips and then it attained an approximately constant value. The standard deviations observed (Table 2) indicate that the mean hyphal extension rate is a reproducible feature of the mycelium of each species.

It has previously been suggested 'that the mean rate of hyphal extension of spco $I$ varies directly with the organism's specific growth rate when the latter is varied by temperature' (Trinci, I973a). The ratio, mean hyphal extension rate of mycelia of spco I (Table 2): the organism's specific growth rate in submerged culture (Trinci, 1973a) was 8I at $25^{\circ} \mathrm{C}$ and 80 at $37^{\circ} \mathrm{C}$. This result supports the hypothesis that under certain conditions the mean 


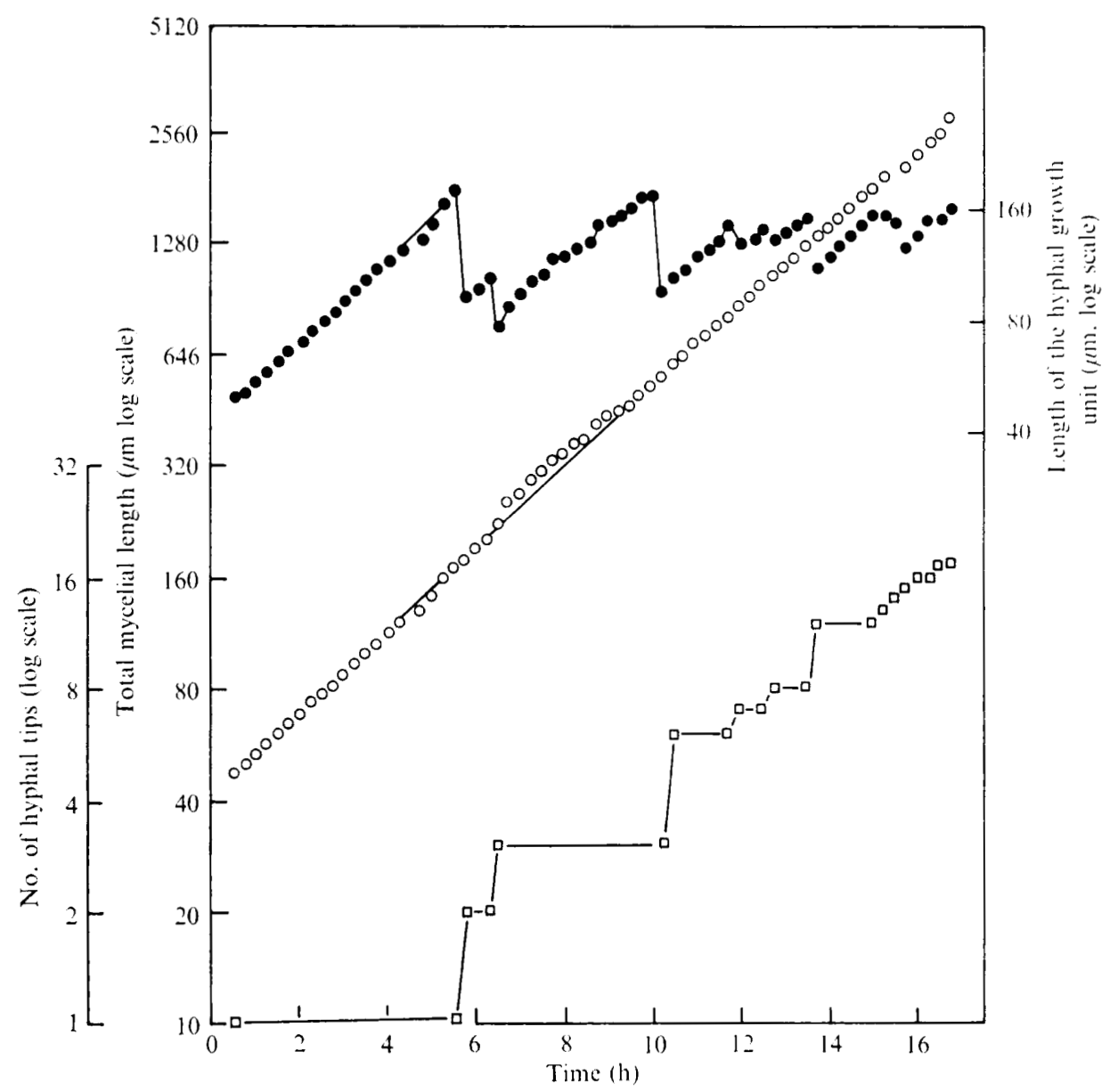

Fig. 2. Growth of a mycelium of Aspergillus nidulans on solid DM medium at $25^{\circ} \mathrm{C}$. $\square$, No. of tips; $\bigcirc$, total hyphal length; $\bigcirc$, hyphal growth unit.

hyphal extension rate of a mycelium is directly related to the organism's specific growth rate.

The growth of a mycelium of Mucor hiemalis during a $\mathrm{I}$ h period is shown in Table 3 and Fig. 7; during this period the total length of the mycelium increased from 376I to $7136 \mu \mathrm{m}$ and five additional growing points were produced. The extension rate of hyphae present throughout the I h period varied from 2I to $329 \mu \mathrm{m} / \mathrm{h}$. There was sometimes no correlation between the length of a branch and its extension rate (cf. branches 5 and 9 with 14 and I 5 respectively, Table 3). The extension rate of some branches (e.g. I5 and I7, Table 3) exceeded the maximum which would have been predicted from the organism's specific growth rate, i.e. the specific growth rate of these branches was much faster than that of the whole mycelium. It seems clear that these particular branches could only have achieved the observed growth rates if other parts of the mycelium had contributed to their extension. Thus the initial growth of a branch may be dependent upon its parent mycelium (Trinci, I970).

Some branches produced by mycelia did not subsequently grow, grew at a very slow rate or only grew after a lag of several hours. The position of such branches in relation 


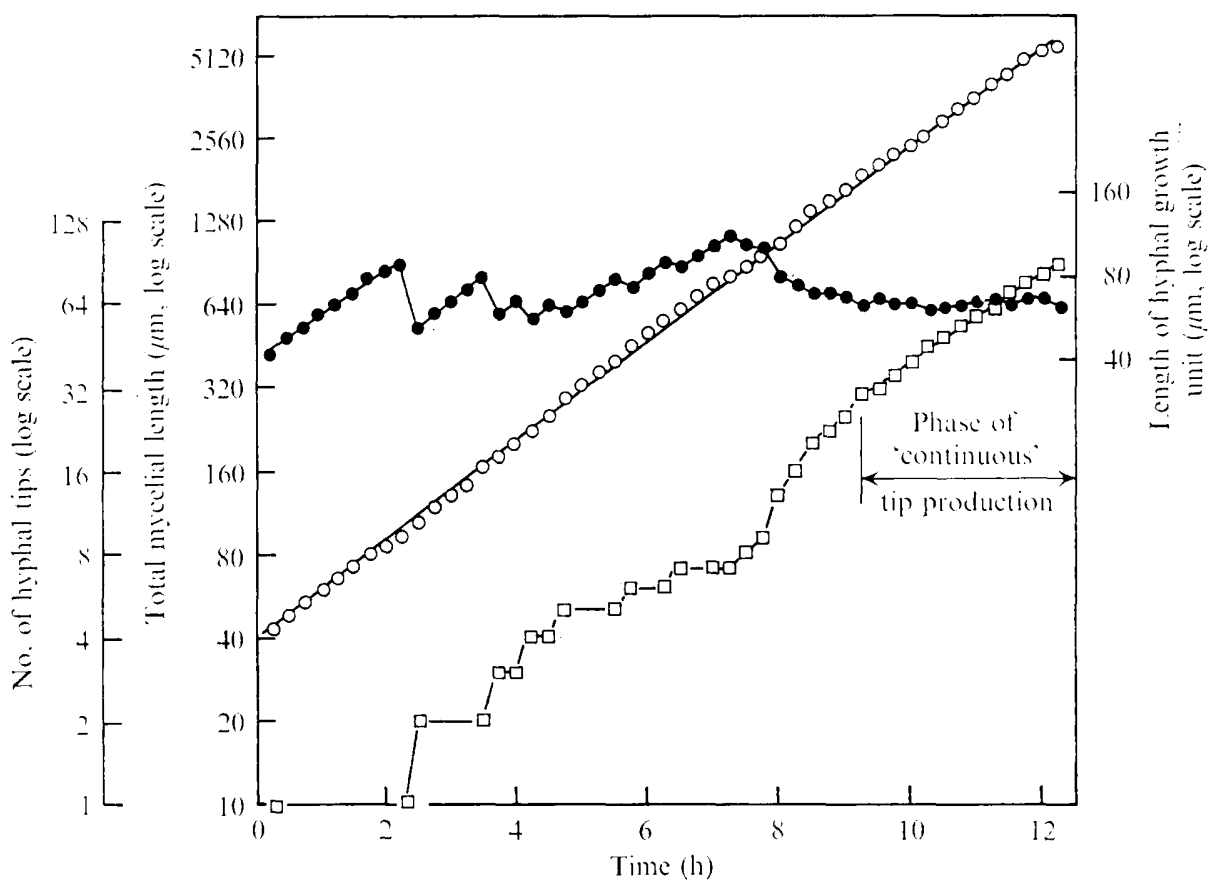

Fig. 3. Growth of a mycelium of Neurospora crassa on solid Vogel's medium at $25 \mathrm{C}$.

$\square$, No. of tips; $\bigcirc$, total hyphal length;, hyphal growth unit.

to other growing points may account for their slow growth rate, e.g. the slow growth rate (Table 3) of branch 6 in Fig. 7 may have been a consequence of the fact that protoplasm synthesized in the main hypha was directed primarily to tips $I$ and 7 rather than tip 6 .

However, there was usually some degree of correlation between the extension rate of a branch and its length. Fig. 8 shows the relationship between mean length and growth rate of branches of young mycelia of Mucor hiemalis, Geotrichum candidum and Aspergillus nidulans. The fact that the curves in Fig. $8 a$ and $b$ would, if extrapolated, cut the vertical axis significantly above a zero growth rate is a further indication that the initial rate of extension of a branch is dependent upon its parent mycelium. The maximum extension rates of $M$. hiemalis, $G$. candidum and $A$. nidulans were first attained when their branches were about 850,400 and $400 \mu \mathrm{m}$ long respectively. The peripheral growth zones of 'mature' colonies of $G$. candidum and $A$. nidulans were about 420 and $660 \mu \mathrm{m}$ wide respectively (Trinci, I97I $a$ ). The hyphal growth unit is the mean length of hypha which contributes protoplasm to the extension of the tips of a mycelium, whilst the peripheral growth zone is the maximum length of hypha which contributes to the extension of the leading hyphal tips of a 'mature' colony. In both cases the extension rate is a function of the length of hypha which contributes protoplasm to apical growth and of the organism's specific growth rate (Trinci, I97I $a$ ).

In Table 2, the maximum extension rates (Fig. 8) of the branches of young mycelia are compared with the radial growth rates of their 'mature' colonies. 


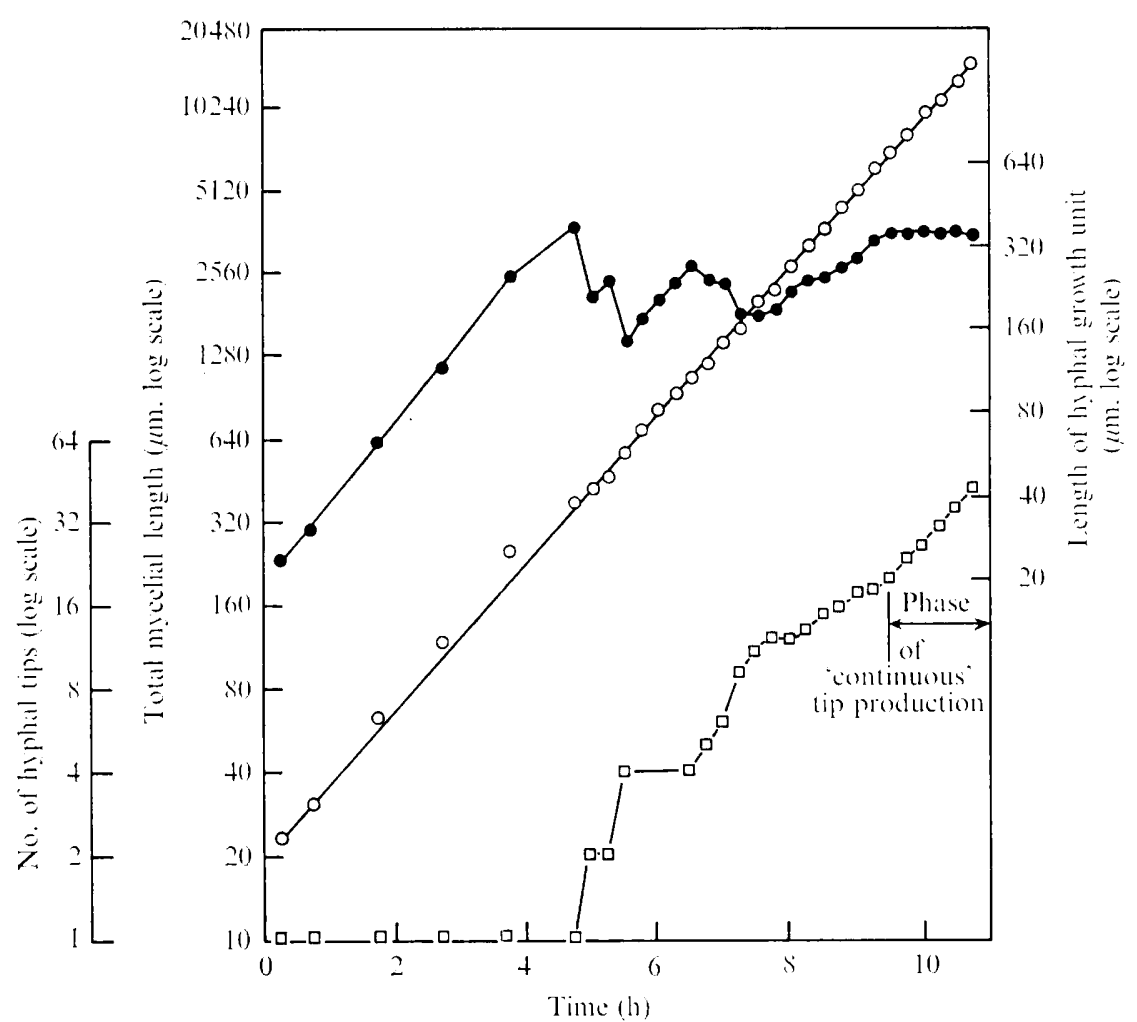

Fig. 4. Growth of a mycelium of Mucor hiemalis on malt extract agar at $25^{\circ} \mathrm{C}$.

$\square$, No. of tips; $\bigcirc$, total hyphal length; $\bullet$, hyphal growth unit.

\section{DISCUSSION}

The present results confirm the hypothesis (Caldwell \& Trinci, I973; Trinci, 1973 $a$ ) that growth of a mycelium involves the duplication of a 'growth unit' which consists of a tip and a certain mean length of hypha. The hyphal growth unit is strain specific but is influenced by certain environmental conditions (Trinci, 1973a).

As defined above (eqn. 2) the 'growth unit' of a mycelium is simply the mean length of hypha per tip, and it clearly differs qualitatively from the 'growth units' (i.e. cells) of bacteria and yeasts. However, the present results indicate that branch initiation, like the division of a single cell, may be regulated by the changes in cytoplasmic volume which accompany growth, i.e. when the mean hyphal growth unit of a mycelium (volume of cytoplasm per tip) exceeds a critical length (volume) a new branch is initiated.

After spore germination growth is initially completely integrated but as the mycelium increases in size the degree of integration will become progressively less as parts of the mycelium become independent. This loss of integration within a mycelium will occur earlier in species such as Geotrichum candidum which have complete septa (i.e. lack pores) than in species such as Aspergillus nidulans which have incomplete septa (i.e. possess pores).

The small vesicles which accumulate at the tips of fungal hyphae (Grove, Bracker \& Morre, I970; Trinci \& Collinge, I973) are thought to contain cell-wall precursors (Bartnicki-Garcia, 1973) and possibly the enzymes which lyse wall polymers. The maximum 

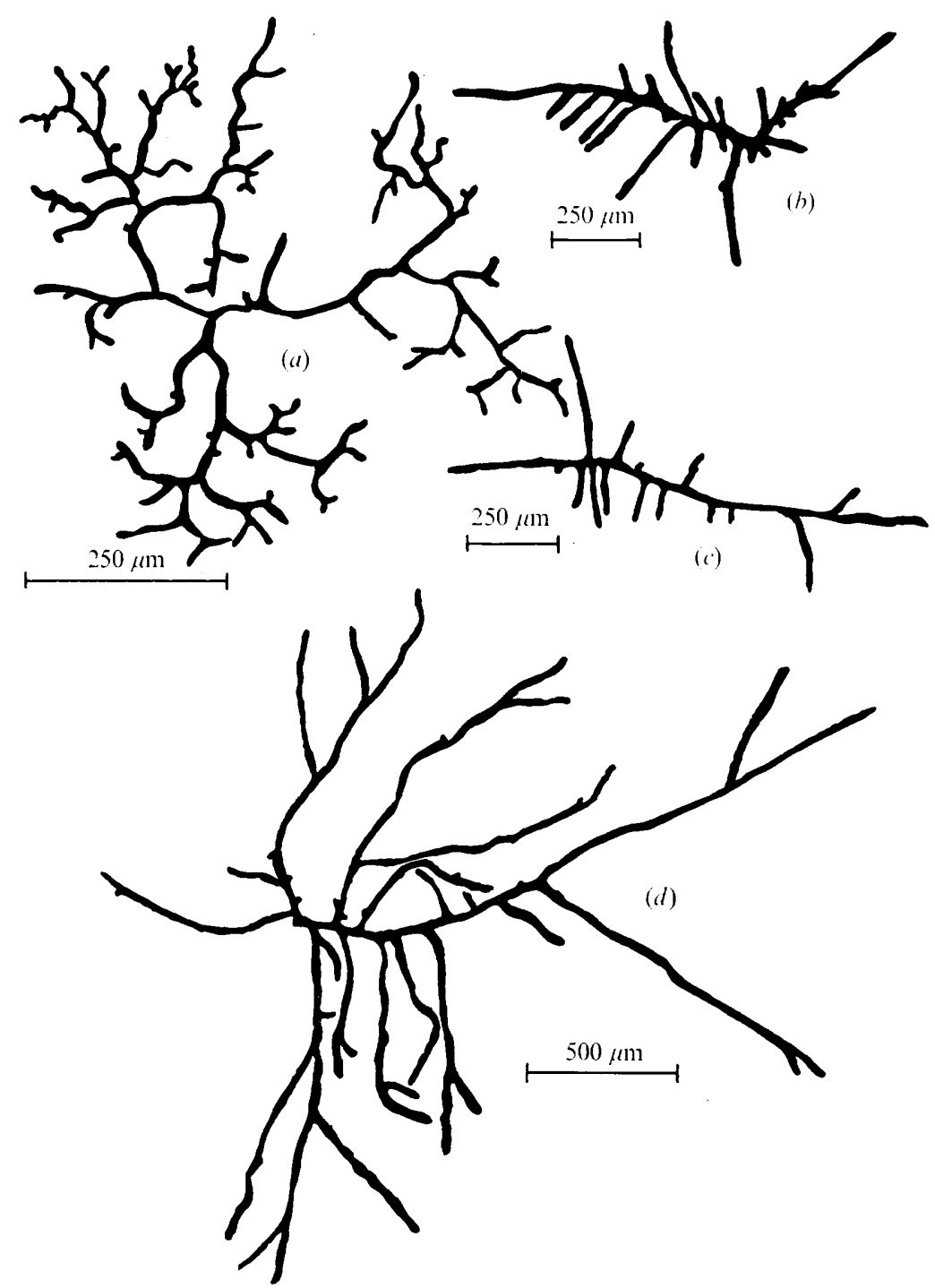

Fig. 5. Final appearance of the mycelia whose growth is recorded in Fig I to 4. (a) Neurospora crassa; (b) Geotrichum candidum; (c) Aspergillus nidulans; (d) Mucor hiemalis.

extension rate of a hyphal tip (the rate of linear growth) may be determined either by the rate at which these vesicles fuse with the tip wall or the rate of synthesis of wall polymers. The rate of vesicle production per unit volume of cytoplasm is probably constant for a given set of conditions. Thus the mean rate of vesicle supply per tip will be directly related to the mean length of the hyphal growth unit. When the rate of vesicle production exceeds the rate at which they fuse with the hyphal wall their concentration in the cytoplasm will increase. Due to the polarity which is established within hyphae (Bartnicki-Garcia, I973) the vesicles will tend to accumulate at specific regions within the mycelium (e.g. behind tips and septa) rather than be uniformly distributed throughout the cytoplasm. Branch initiation may occur when the rate at which the vesicles fuse with the hyphal wall exceeds a certain minimum. 
Table I. Hyphal length and hyphal tip specific growth rates of mycelia

Species

\section{Aspergillus nidulans}

Geotrichum candidum

Mucor hiemalis

Penicillium chrysogenum

Neurospora crassa spco 1

Neurospora crassa spco 1
Temperature $\left({ }^{\circ} \mathrm{C}\right)$

25
25
25
25
25
37

Specific growth rate*

$\overbrace{\substack{\text { Hyphal length, } \\\left(\mathrm{h}^{-1}\right)}}$ No. of hyphal tips, $\alpha_{t} \uparrow$

$0.23 \pm 0.02$

$0.40 \pm 0.01$

$0.56 \pm 0.03$

$0.28 \pm 0.02$

$0.38 \pm 0.05$

$0.52 \pm 0.05$

* Each specific growth rate is the mean of three to five observations; specific growth rates were calculated from In $2 / T_{d}$, where $T_{d}=$ doubling time (Trinci, I97 $a$ ). Standard deviations are also given.

$\dagger$ Tip specific growth rates were calculated during the period of 'continuous' tip formation.

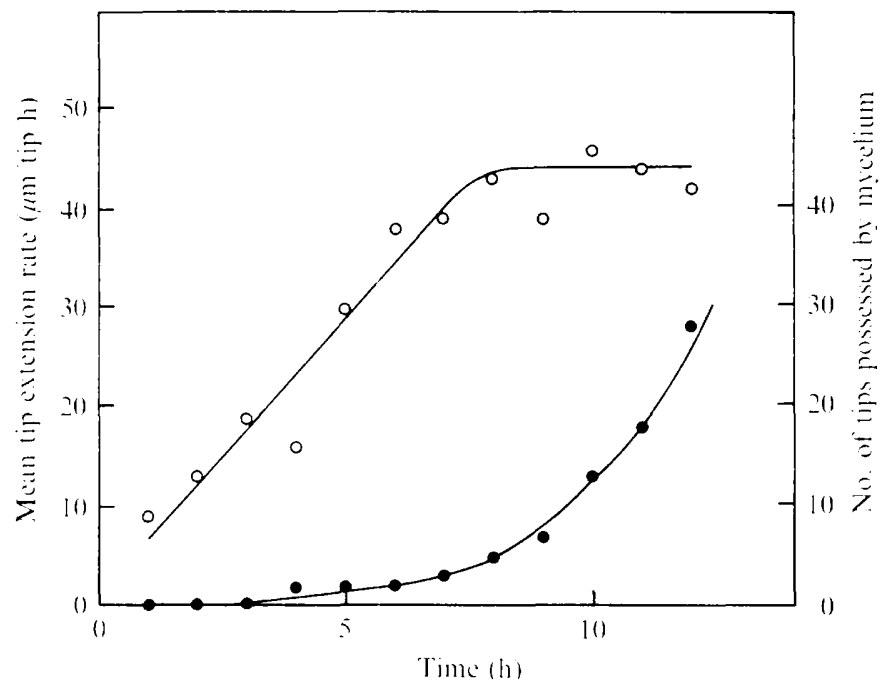

Fig. 6. Mean hyphal extension rate of a mycelium of Geotrichum candidum.

-, No of tips; $\mathrm{C}$, mean tip extension rate.

Table 2. Mean hyphal extension rate of 'young' mycelia, maximum hyphal extension rate of branches of 'young' mycelia and mean colony radial growth rate of 'mature' colonies

\begin{tabular}{|c|c|c|c|c|}
\hline Species & Temperature $\left({ }^{\circ} \mathrm{C}\right)$ & $\begin{array}{c}\text { Mean hyphal } \\
\text { extension rate } \\
E \text {, of 'young' } \\
\text { mycelia on } \\
\text { cellophane } \\
(\mu \mathrm{m} / \mathrm{tip} / \mathrm{h})\end{array}$ & $\begin{array}{c}\text { Maximum hyphal } \\
\text { extension rate } \\
\text { of 'young' } \\
\text { mycelia } \\
(\mu \mathrm{m} / \mathrm{h})\end{array}$ & $\begin{array}{l}\text { Mean colony } \\
\text { radial growth } \\
\text { rate of } \\
\text { 'mature' colonies } \\
\text { on cellophane } \\
(\mu \mathrm{m} / \mathrm{h})\end{array}$ \\
\hline Aspergillus nidulans & 25 & $33 \pm 4$ & 80 & 127 \\
\hline Geotrichum candidum & 25 & $48 \pm 3$ & 120 & 132 \\
\hline Mucor hiemalis & 25 & I $25 \pm$ I I & 325 & 377 \\
\hline Penicillium chrysogenum & 25 & $8 \pm 0.3$ & - & 一 \\
\hline Neurospora crassa spco 1 & 25 & $2 I \pm 4$ & 49 & 343 \\
\hline Neurospora crassa spco 1 & 37 & $38 \pm 7$ & - & 894 \\
\hline
\end{tabular}


Table 3. Increase in length of a mycelium of Mucor hiemalis during $a$ I $h$ period of growth at $25,{ }^{\circ} \mathrm{C}$

$\begin{array}{cccr}\begin{array}{c}\text { Tip no.* } \\ \text { (see Fig. 7) }\end{array} & \begin{array}{c}\text { Original length of } \\ \text { branch }(\mu \mathrm{m})\end{array} & \begin{array}{r}\text { Final length of } \\ \text { branch }(\mu \mathrm{m})\end{array} & \begin{array}{r}\text { Increase in } \\ \text { during per } \\ \text { observation }\end{array} \\ \text { I } & 1230 & 1544 & 314 \\ 2 & 458 & 787 & 329 \\ 3 & 501 & 787 & 286 \\ 4 & 472 & 736 & 264 \\ 5 & 129 & 329 & 200 \\ 6 & 36 & 57 & 21 \\ 7 & 286 & 615 & 329 \\ 8 & 207 & 458 & 25 \mathrm{I} \\ 9 & 122 & 300 & 178 \\ 10 & 72 & 229 & 157 \\ \text { II } & 93 & 243 & 150 \\ 12 & 86 & 272 & 186 \\ 13 & 2 \mathrm{I} & 136 & 115 \\ 14 & 43 & 243 & 200 \\ \text { I5 } & 7 & 157 & 150 \\ 16 & - & 64 & 64 \\ 17 & - & 143 & 143 \\ \text { I8 } & - & 14 & 14 \\ 19 & - & 14 & 14 \\ 20 & - & 21 & 21\end{array}$

* The branches are numbered in the order in which they were produced. Branches 16 to 20 were formed during the $\mathrm{I} h$ observation period.

The appearance of the mycelium at the start and end of the observation period is shown in Fig. 7.

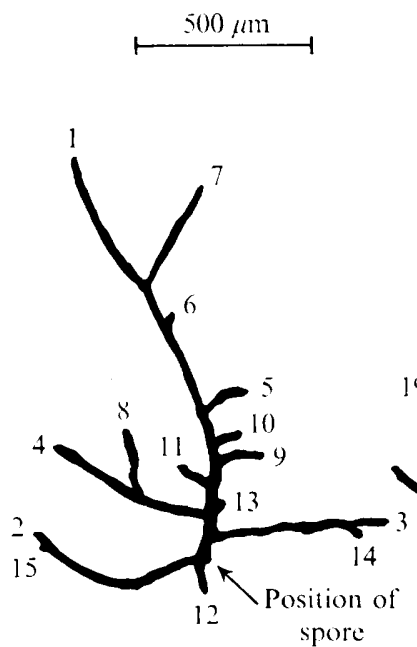

(a)

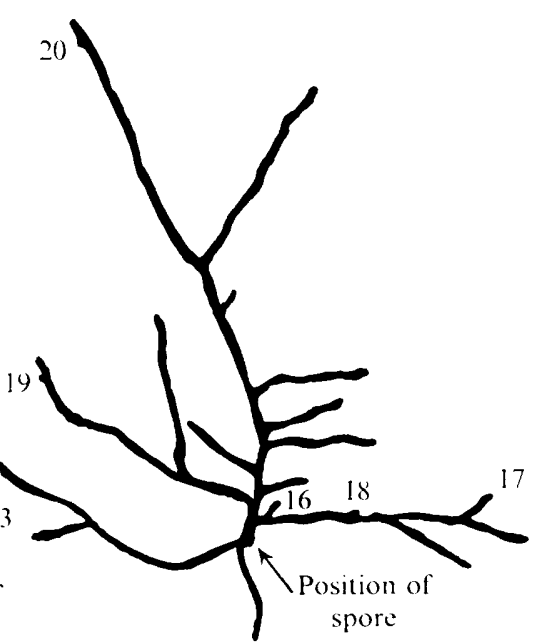

(b)

Fig. 7. Growth of a mycelium of Mucor hiemalis. (a) Appearance of the mycelium at zero time; (b) appearance of the mycelium after I h growth at $25^{\circ} \mathrm{C}$. Branches are numbered in the order in which they were produced. The growth rates of the branches are shown in Table 3 . 


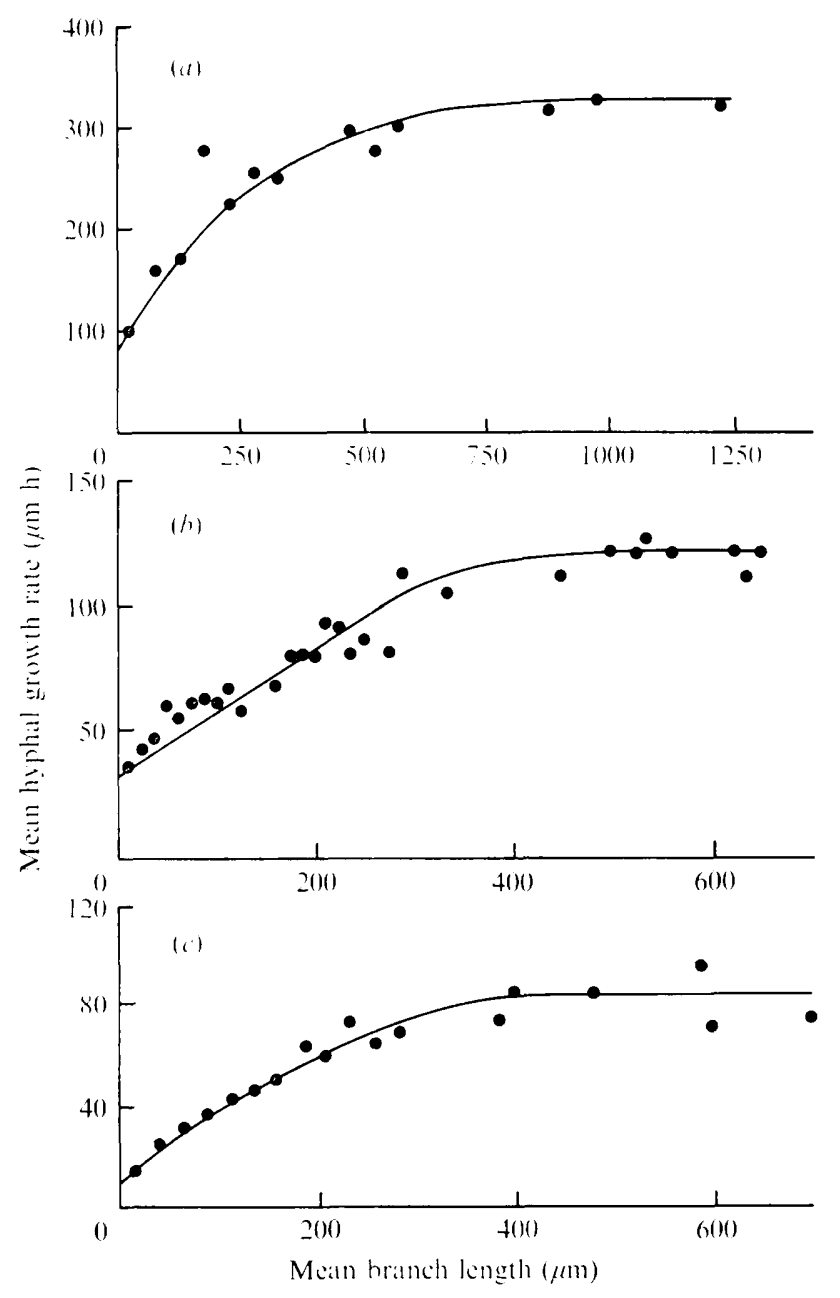

Fig. 8. Relationship between mean branch length and mean extension rate of (a) Mucor hiemalis, (b) Geotrichum candidum, and (c) Aspergillus nidulans, at $25^{\circ} \mathrm{C}$. Each point is the mean of 5 to 12 branches.

Certainly the formation of branches from the septa of damaged hyphae of Neurospora crassa is preceded by an accumulation of vesicles behind the septa (Trinci \& Collinge, 1974). Further branch initiation in Geotrichum candidum is associated with septum formation (A. P. J. Trinci, unpublished? observation). The hypothesis that vesicles are not uniformly distributed in the cytoplasm is supported by the observation that new branches are formed before all the existing tips of a mycelium have attained the maximum extension rate (Table 3 ). The present hypothesis would predict that any mutation or factor which reduces the maximum rate of tip extension without affecting the rate of vesicle production would result in an increase in the frequency of branch initiation without reducing the overall rate of hypha formation (i.e. the organism's specific growth rate). The spreading colonial mutants of Neurospora crassa may be such mutants (Trinci, I973a, $b$ ) and L-sorbose such a factor (Trinci \& Collinge, 1973). 
The observed dampening of the oscillations in hyphal growth unit length (Fig. I) is consistent with the present theory of mycelial growth, i.e. a new branch is initiated when the mean volume of cytoplasm per tip exceeds a certain critical value. The effect of the initiation of a new branch on the length of the hyphal growth unit will decrease as the total length of the mycelium increases. The present results imply a certain degree of integration of the growth within a mycelium.

The decrease in germ-tube specific growth rate which was previously observed (Trinci, 197I $b$ ) was almost certainly due to oxygen limitation in the small growth chambers employed (Trinci, 1969). In the present investigation, in which the fungi were grown in Petri dishes, a mycelium of Mucor hiemalis continued to grow exponentially even when its total length had exceeded Io mm (Fig. 4). Eventually, when the hyphal density per unit surface area exceeds a certain minimum, a mycelium will cease to grow exponentially. The onset of this reduction in growth rate will presumably be related to the length of the hyphal growth unit, i.e. fungi which produce a sparse mycelium (e.g. M. hiemalis) will grow exponentially for a longer period than fungi which produce a dense mycelium (e.g. Penicillium chrysogenum).

The maximum extension rate of branches formed by young mycelia of Geotrichum candidum and Mucor hiemalis were similar to the radial growth rate of their 'mature' colonies (Table 2; Fig. 8). However, in Aspergillus nidulans and Neurospora crassa the observed difference in these two parameters indicates that differentiation during the formation of a 'mature' colony results in the production of leading hyphae which have a significantly faster growth rate than the branches of their young mycelia (Trinci, I973a).

I would like to thank the Science Research Council for supporting this research.

\section{REFERENCES}

Bartnicki-Garcia, S. (1973). Microbial differentation. Symposia of the Society for General Microbiology 23, pp. $245-268$.

Caldwell, I. Y. \& Trincr, A. P. J. (1973). The growth unit of the mould Geotrichum candidum. Archiv für Mikrobiologie 88, 1-10.

Grove, S. N., Bracker, C. E. \& Morre, D. J. (1970). An ultrastructural basis for hyphal tip growth in Pythium ultimum. American Journal of Botany 59, 245-266.

Plomley, N. J. B. (1959). Formation of the colony in the fungus Chaetomium. Australian Journal of Biological Sciences 12, 53-64.

TrincI, A. P. J. (1969). A kinetic study of the mode of growth of Aspergillus nidulans and other fungi. Journal of General Microbiology 57, 1 1-24.

Trinci, A. P. J. (1970). Kinetics of apical and lateral branching in Aspergillus nidulans and Geotrichum lactis. Transactions of the British Mycological Society 55, 17-28.

TRINCI, A. P. J. ( $197 \mathrm{I} a$ ). Influence of the peripheral growth zone on the radial growth rate of fungal colonies. Journal of General Microbiology 67, 325-344.

TRINCI, A. P. J. (1971 b). Exponential growth of the germ tubes of fungal spores. Journal of General Microbiologv $67,345-348$.

TRINCI, A. P. J. (1973a). The hyphal growth unit of wild type and spreading colonial mutants of Neurospora crassa. Archiv für Mikrobiologie 91, I27-136.

TRINCI, A. P. J. (I973b). Growth of wild type and spreading colonial mutants of Neurospora crassa in batch culture and on agar medium. Archiv für Mikrobiologie 91, I13-126.

TRINCI, A. P. J. \& BANBury, G. (I967). A study of the growth of the tall conidiophores of Aspergillus giganteus. Transactions of the British Mycological Society 50, 525-538.

TRINCI, A. P. J. \& Collinge, A. (1973). Influence of L-sorbose on the growth and morphology of Neurospora crassa. Journal of General Microbiology 78, 179-192. 
Trinci, A. P. J. \& Collinge, A. (1974). Occlusion of the septal pores of damaged hyphae of Neurospora crassa by hexagonal crystals. Protoplasma (in the Press).

Vogel, H. J. (1956). A convenient growth medium for Neurospora (medium N). Microbiology and Genetical Bulletin $\mathrm{x3}, 4 \mathrm{~L}$.

Zalokar, M. (1959). Enzyme activity and cell differentiation in Neurospora. American Journal of Botany $46,555-559$. 